\title{
Technologies for all-optical wavelength conversion in DWDM networks
}

\author{
Wolfson, David; Fjelde, Tina; Kloch, Allan
}

\section{Published in:}

Proceedings on The 4th Pacific Rim Conference on Lasers and Electro-Optics

Link to article, DOI:

10.1109/CLEOPR.2001.971089

Publication date:

2001

Document Version

Publisher's PDF, also known as Version of record

Link back to DTU Orbit

Citation (APA):

Wolfson, D., Fjelde, T., \& Kloch, A. (2001). Technologies for all-optical wavelength conversion in DWDM networks. In Proceedings on The 4th Pacific Rim Conference on Lasers and Electro-Optics (Vol. 2) https://doi.org/10.1109/CLEOPR.2001.971089

\section{General rights}

Copyright and moral rights for the publications made accessible in the public portal are retained by the authors and/or other copyright owners and it is a condition of accessing publications that users recognise and abide by the legal requirements associated with these rights.

- Users may download and print one copy of any publication from the public portal for the purpose of private study or research.

- You may not further distribute the material or use it for any profit-making activity or commercial gain

- You may freely distribute the URL identifying the publication in the public portal 


\section{ThB3-3 (Invited)}

\section{Technologies for all-optical wavelength conversion in DWDM networks}

D. Wolfson, T. Fjelde and A. Kloch

COM, Technical University of Denmark, BIdg. 349, DK-2800 Lyngby, Denmark

Telephone: +45 4525 3773, Fax: +45 45936581 , e-mail: dw@com.dtu.dk

Abstract

inherent when performing wavelength conversion and has been

Different techniques for all-optical wavelength conversion are reviewed and the advantages and disadvantages seen from system perspective are highlighted.

Introduction

The trends in optical communication systems today clearly show that WDM systems are being installed on a global scale in orde to accommodate the increasing need for capacity. As WDM deployment continues, there will be a need to manage the capacity on the optical channel layer, which will boost the demand for optical cross-connects. In these systems, wavelength conversion is an important functionality since it, e.g., enables wavelengths to be assigned on a link-to-link basis, thereby relaxing the requirements to the wavelength management throughout the network.

Therefore, all-optical wavelength conversion will play a major role in making cost-effective network nodes in future high-speed WDM networks, where functions such as switching and routing in the optical domain also are envisaged. Consequently, this paper focuses on different techniques for high-speed all-optical wavelength conversion.

\section{Four-wave mixing}

Converters that rely on four-wave mixing (FWM) have been investigated using optical fibers [1], laser converters [2] and SOAs [3] as non-linear elements. FWM converters have severa desirable features such as format transparency, high-speed operation (100 Gbit/s conversion is shown in [4]) and the ability to convert several WDM channels simultaneously (32x10 Gbit/s conversion is shown in [5]).

A problem associated with FWM, however, is that the conversion efficiency is low (typically below $-10 \mathrm{~dB}$ ), why high optical powers have to be used for both the pump and signal (10$20 \mathrm{dBm}$ ). Furthermore, the efficiency decreases as the detunin between the pump and signal wavelength increases, thereby limiting the conversion range [6]. Using two orthogonal polarised pumps solves the problem of wavelength-dependent efficiency [7,8] and can result in polarisation insensitive operation [9], however, at the expense of added complexity. Still, as a result of low efficiencies, the converted signals usually exhibit low optical signal-to-noise ratios (OSNR). As shown in [10], where two converters are cascaded at $10 \mathrm{Gbit} / \mathrm{s}$, an initia OSNR of $\sim 40 \mathrm{~dB}$ is reduced to $\sim 20 \mathrm{~dB}$ after two conversions. Although the OSNR can be improved by using a pre-filtering technique [11], the cascadability performance of FWM-based converters still needs to be demonstrated. Moreover, since the output wavelength is dependent on both the pump and signal wavelengths, the pump must be tuneable even for fixed output wavelengths.

Electro-absorption converters

Wavelength converters based on electro-absorption (EA) are very simple devices and recently BER measurements for conversion at $10 \mathrm{Gbits}$ over $20 \mathrm{~nm}$ was reported with negligible polarisation sensitivity [12]. Furthermore, conversion a $40 \mathrm{Gbit} / \mathrm{s}$ has also been achieved with high Q-values [13]. Due to the highly non-linear transfer function of EAs, a 2R capability is

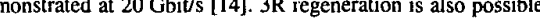
simply by replacing the $\mathrm{CW}$ light, necessary for wavelength conversion, with a re-timed optical clock signal [15]. This has been used to demonstrate $3 R$ regeneration both at 10 and $40 \mathrm{Gbit} / \mathrm{s}[16,13]$.

The main drawbacks of EA conyerters are low conversion efficiencies, high insertion losses and the need for high optical input powers to achieve good absorption modulation (typically 10-15 dBm) [12].

\section{Cross-gain modulation in SOAs}

These types of converters are also very simple and the scheme is polarisation insensitive, has a conversion range in excess of $50 \mathrm{~nm}$ [17], large input power dynanic range (typically $>7 \mathrm{~dB}$ ), is very power efficient and high-speed operation is possible. Even conversion at bit rates beyond the limit of what the carrier lifetime dictates is possible, which is due to a self-filtering effect in long SOAs with small intrinsic losses. Thereby, $100 \mathrm{Gbit}$ conversion is shown in a $2-\mathrm{mm}$ long device [18], clearly exceeding the typical carrier lifetime ( $20-50 \mathrm{ps})$.

There are, however, also some shortcomings related to XGM. The scheme suffers from a chirped output signal limiting the transmission distance on non-dispersion shifted fibers and the extinction ratio for the converted signal may degrade for conversion to longer wavelength [19].

Cross-phase modulation in SOAs

A technique that eliminates most of the drawbacks of the previous schemes is based on cross-phase modulation in SOAbased interferometers. Non-linear optical loop mirrors (using SOAs [20] or fibers [21] as the non-linear element), ultra fast non-linear interferometers [22], delayed-interference signal wavelength converters (DISC) [23], Mach-Zehnder (MZI) [24] and Michelson interferometers (MI) [25] have been proposed. The integrated interferometers, i.e., the DISC, MZI and MI, seem preferable seen from a system perspective, however, due to stability issues and compactness. The DISC configuration has recently shown impressive performance in that wavelength conversion at $168 \mathrm{Gbit} / \mathrm{s}$ was achieved [26]. Focusing on the MZI and MI, they can be realised either as an active/passive structure [27], where only the interferometer arms are active or as an all-active structure [281, where the input/output sections active/passive structures are easier to control (only two electrodes to the device are necessary), the all-active structures are easier to realise Furthermore, the active input sections can be used as power equalisers $[29,30]$ as well as pre-amplifiers allowing for very low optical input power [29]. The active output section, on the output power of the converted signal [31] thereby resulting in excellent power efficiencies. Moreover, the following attractive features characterise the MZIs and MIs: High-speed operation (40 Gbit/s conversion is shown in $[30,32])$, low and controllable chirp [19] and a large conversion range [32] are all possible. Inverting or non-inverting operation of the interferometric converter can be obtained by operating on either the negative or positive slope of the transfer function. Also, a high OSNR of the

II -574 
converted signal is achieved (typically $-40 \mathrm{~dB}$ in $0.1 \mathrm{~nm}$ [33]) and all-optical $2 \mathrm{R}$ regeneration inherent due to the non-linear transfer function. Furthermore, if an optical clock signal is used instead of the $\mathrm{CW}$ light, re-timing can also be obtained [34] (2R and $3 R$ regeneration at $40 \mathrm{Gbit} / \mathrm{s}$ is shown in [33]). Owing to these excellent features, an impressive cascadability performance has been demonstrated in loop experiments (1000 3R regenerators at $10 \mathrm{Gbit} / \mathrm{s}[35]$ and 200 at $20 \mathrm{Gbit} / \mathrm{s}$ [36], where each regenerator consist of two MZIs).

A new type of interferometric converters has also recently attracted attention, namely dual-order mode interferometers. By proper design of the device it is achieved that the original data signal is absorbed in an unpumped waveguide, whereas, the converted signal is guided to the output of the converter [37]. Consequently, conversion to the same wavelength as the input signal is possible in a co-directional propagation scheme as well as filter-less operation. The latter is clearly an important feature in cases where a tunable output wavelength is required. This device type has shown excellent performance at $10 \mathrm{Gbit/s}$ over the entire EDFA window [38] and also initial results at $20 \mathrm{Gbit} / \mathrm{s}$ are promising [38].

It should mentioned that since the performance of the interferometric devices is sensitive to the phase conditions between the interferometer arms, active control of interferometric wavelength converters is an issue that needs special attention.

Summary

All-optical wavelength conversion will be important for construction of cost-effective network nodes and flexible WDM systems. Although the emphasis here has been on SOA-based converters, there are numerous approaches for all-optical wavelength conversion. At the same time researchers all over the world are constantly looking for new methods, while investigation of already existing techniques is ongoing and giving promising results. The specific requirements to a practical all-optical converter will clearly be system dependent but issues like compactness, ease of implementation and control as well as cascadability will all be important aspects. Naturally, also the ability to operate at very high bit rates will play an important role in choosing the optimum solution.

References

[1] K. Inoue et al., IEEE Photonics Technology Letters, 7, pp. 327-329 (1995)

[2] M. F. C. Stephens et al., Electronics Letters, 35, pp. 420421 (1999).

[3] T. J. Morgan et al., IEEE Photonics Technology Letters, 11, pp. 982-984 (1999).

[4] A. E. Kelly et al., Electronics Letters, 34, pp. 1955-1956 (1998).

[5] S. Watanabe et al,, In Proceedings of ECOC'98, post deadline paper, pp. 85-87, Madrid, Spain (1998).

[6] A. D'Ottavi et al., IEEE Photonics Technology Letters, 10. pp. 952-954 (1998).

[7] T. J. Morgan et al., IEEE Photonics Technology Letters, 10. pp. 1401-1403 (1998).

[8] T. J. Morgan et al., IEEE Photonics Technology Letters, 11. pp. 982-984 (1999).

[9] S. Watanabe et al., Electronics Letters, 33, pp. 316-317 (1997)

[10] R. B. Lee et al., IEEE Photonics Technology Letters, 9, pp. 752-754 (1997)
[11] F. Geraghty et al. IEEE Photonics Technology Letters. 9. pp. 452-454 (1997)

12] L. Oxenloewe et al., In Proceedings of ECOC2000, Vol. 3, pp. 303-304, Munich, Germany (2000)

[13] T. Otani et al., In Technical Digest of OFC2000, paper ThP3, Baltimore, USA (2000).

[14] P. S. Cho et al., IEEE Photonics Technology Letters, 11, pp. 1662-1664 (1999)

[15] T. Miyazaki et al., In Technical Digest of OFC'99, paper WM53, San Diego, USA (1999).

[16] T. Otani et al., IEEE Photonics Technology Letters, 12, pp 431-433 (2000).

[17] C. Joergensen et al., IEEE Journal of Selected Topics in Quantum Electronics, 3, pp. 1168-1180 (1997).

[18] A. D. Ellis et al., Electronics Letters, 34, pp. 1958-1959 (1998).

[19] T. Durhuus et al., IEEE Joumal of Lightwave Technology. 14, pp. 942-954 (1996).

[20] M. Eiselt et al., Electronics Letters, 29, pp. 107-109 (1993)

21) K. A. Rauschenbach et al., IEEE Photonics Technology Letters, 6, pp. 1130-1132 (1994).

[22] N. S. Patel et al. IEEE Photonics Technology Letters, 8 pp. 1695-1697 (1996).

23] Y. Ueno et al., IEEE Photonics Technology Letters, 9, pp. 346-348 (1998).

[24] T. Durhuus et al., IEEE Photonics Technology Letters, 6, pp. $53-55$ (1994)

[25] B. Mikkelsen et al., Electronics Letters, 30, pp.260-261 (1994).

26] Y. Ueno et al., In Proceedings of ECOC2000, Vol. 1, pp. 13-14. Munich, Germany (2000)

27] R. Hess et al., In Technical Digest of OAA 97, post deadline paper, PD7, Victoria, Canada (1997)

[28] B. Dagens et al., IEEE Photonics Technology Letters, 11, pp. 424-426 (1999).

[29] C. Janz et al., Electronics Letters, 35, pp. 588-590 (1999).

[30] D. Wolfson et al., In Proceedings of ECOC'99, paper WeB4.5, Nice, France (1999).

[31] D. Wolfson et al., In Proceedings of OECC'99, pp. 456457, Beijing, China (1999).

[32] B. Mikkelsen et al., Electronics Letters, 33, pp. 2137-2139 (1997).

[33] D. Wolfson et al., IEEE Photonics Technology Letters, 12 , pp. 332-334 (2000)

[34] K. S. Jepsen et al., Electronics Letters, 34, pp. 472-474 (1998)

[35] B. Lavigne et al., In Technical Digest of OFC'99, paper TuJ3, San Diego, USA (1999).

[36] B. Lavigne et al., In Technical Digest of OFC2000, paper ThF7, Baltimore, USA (2000).

[37] C. Janz et al., Electronics Letters, 34, pp. 1848-1849 (1998).

[38] D. Wolfson et al., In Technical Digest of OFC2000, paper TuF3, Baltimore, USA (2000) 